\title{
Effect of Processing Parameters on 3D Printing of Cement - based Materials
}

\author{
Jia Chao LIN ${ }^{1}$, Jun WANG ${ }^{1}$, Xiong WU ${ }^{1}$, Wen $\mathrm{YANG}^{1}$, Ri Xu ZHAO${ }^{1}$, Ming BAO ${ }^{1}$ \\ National Enterprise Technology Center, China State Construction Ready Mix Concrete CO., LTD, Wuhan, China
}

\begin{abstract}
D printing is a new study direction of building method in recent years. The applicability of 3D printing equipment and cement based materials is analyzed, and the influence of $3 \mathrm{D}$ printing operation parameters on the printing effect is explored in this paper. Results showed that the appropriate range of $3 \mathrm{D}$ printing operation parameters: print height/nozzle diameter is between 0.4 to 0.6 , the printing speed $4-8 \mathrm{~cm} / \mathrm{s}$ with pumpage $9 * 10^{-2} \mathrm{~m}^{3} / \mathrm{h}$.
\end{abstract}

\section{Introduction}

3D printing, as a rapid prototyping technology, is called "industrial revolution with the manufacturing technology." Compared with traditional manufacturing technology, Through a relatively simple process 3D printing can make the complex shape of the product without mold ${ }^{[1-3]}$. Because of the characteristics of materials saving and energy saving, $3 \mathrm{D}$ printing has the advantages of traditional construction methods in the construction industry, while its low energy consumption, high automation of the building model will greatly expand the diversity of construction methods, an also points the direction of the development for China's construction industry.

\section{Analysis of Printing Equipment and Material Performance}

\subsection{The Status of 3D printing Equipment}

According to the different forming principle, 3D printing technology can be divided into FDM, SLS, SLA, 3DP, LOM, etc. [4]. Due to different forming principles and printing process, 3D printing equipment cannot be universal in different areas, but the equipment operating principle is relatively consistent. Through the installation of $\mathrm{x}, \mathrm{y}, \mathrm{z}$ three axis to achieve the core components of three-dimensional space movement. According to the computer data, the $3 \mathrm{D}$ printer creates a single plane layer by layer until the entire three-dimensional model is created. To the construction plane as a benchmark, 3D printers can be divided into:

(1) Mobile construction plane structure: the construction plane with the work platform in one or two axis direction of movement, with the nozzle work plane to complete the process.

(2) Fixed construction plane structure: transmission mechanism for the $\mathrm{X}, \mathrm{Y}$-axis linkage, $\mathrm{Z}$-axis running alone, the construction plane in the entire printing process does not shift.

\subsection{Performance of Cement - based Materials}

Different from the traditional construction mode, 3D printing puts a more special requirement on the new performance of cement-based materials (rheological properties, plasticity, self-condensation performance). Therefore, 3D printing concrete as a new type of concrete, its performance should meet the following requirements $[5,6]$ :

(1) Good extrudability: Cement-based materials can be formed in the filament after extrusion, cross-section was oval.

(2) Excellent constructability: The deformation of the filamentous concrete in the subsequent stacking process should be minimal.

(3) Controllable working time: The lower concrete quickly harden to provide adequate support strength for the upper layer.

\section{Raw materials and experimental methods}

\subsection{Raw materials}

$\mathrm{P} \cdot \mathrm{O} 42.5$ cement is produced by Hubei Yadong Cement Plant, S95 mineral powder is produced in Xinzhou, Wuhan. And microspheres is produced by Tianjin ZHUXIN New Material Technology Co., Ltd. Their basic performance indexes and particle size distribution are shown in Table 1.

*Corresponding author: Email: Sillybear@yeah.net 
Table 1. Physical Properties of Cement and Mineral Admixtures

\begin{tabular}{cccccc}
\hline Raw Materials & Density $/ \mathrm{g} \cdot \mathrm{cm}^{-3}$ & Specific Surface Area $/ \mathrm{m}^{2} \cdot \mathrm{kg}^{-1}$ & $\begin{array}{c}\text { Water Re- } \\
\text { quirement } \%\end{array}$ & $\begin{array}{c}\text { Fluidity } \\
\text { Ratio } / \%\end{array}$ & 28d Compressive Strength Ratio/\% \\
\hline Cement & 3.20 & 350 & 100 & 100 & 100.0 \\
S95 Slag & 2.80 & 425 & 105 & 100 & 90.1 \\
Microsphere & 2.73 & 710 & 95 & 105 & 83.5 \\
\hline
\end{tabular}

\subsection{Test Methods}

Mortar fluidity test is performed according to the standard for methods of testing uniformity of concrete admixture (GB8077-2012), 3D printing test is performed according to the construction process of project developed equipment with the component quality of the mortar, Cement: Microsphere: Slag Powder: Sand:
Water $=40: 9: 5: 74: 15$. 3D printing equipment is based on the method of FDM, using the fixed construction plane structure. The equipment includes the storage device, the main support frame, the transmission device, the print device, the numerical control device, etc. as shown in Figure 1. And the device parameters are as follows: output displacement of the screw pump $9 * 10^{-2} \mathrm{~m}^{3} / \mathrm{h}$, $\varphi 32 \mathrm{~mm}$ high pressure rubber tube, $\varphi 30 \mathrm{~mm}$ nozzle.

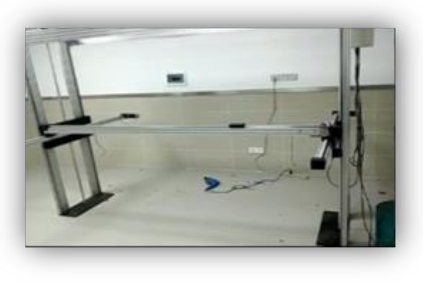

The main support frame

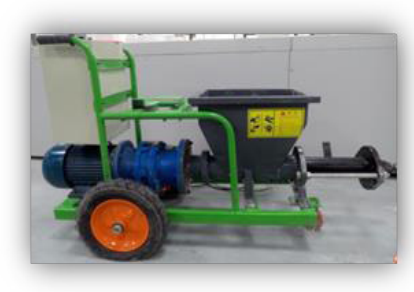

Transportation device

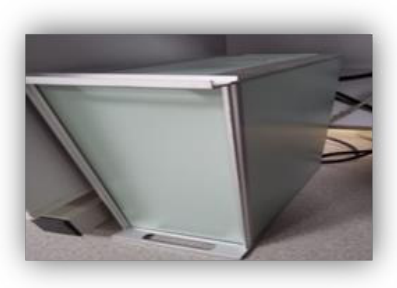

Control device

Fig.1 3D printing equipment

\section{Experimental Results and Discussion}

\subsection{Effect of Material Properties on Process}

By printing $13 \mathrm{~mm}$ layer height closed graphics with running speed $4 \mathrm{~cm} / \mathrm{s}$, the number of stable layers using mortar mix ratio in the chapter 2.2(the fluidity range $150 \sim 290 \mathrm{~mm}$ ) is studied.

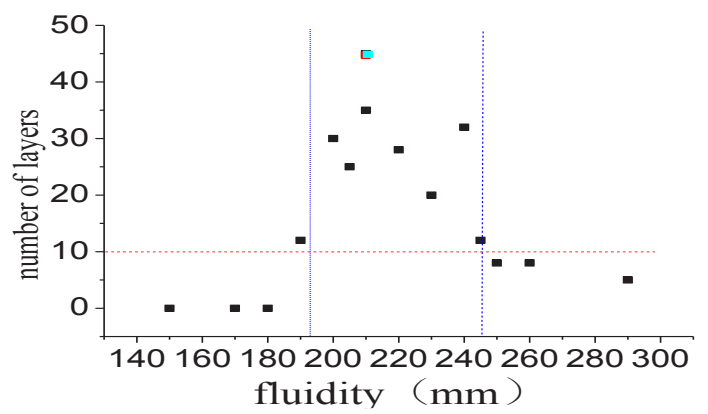

Fig.2 Effect of Material Properties on Process
The results are shown in Fig.2, with the increase of the admixture content, the fluidity of the mortar increase gradually, and the number of 3D stable layers rise first and then decreased. When the fluidity is less than $190 \mathrm{~mm}$, it is prone to extrusion difficulties and intermittent extrusion phenomenon, or even blocking, as shown in Fig.3. When the fluidity is greater than $245 \mathrm{~mm}$, the stable number of layers is not more than 12 layers, as shown in Fig.4. Therefore, when the fluidity between $190-245 \mathrm{~mm}$, the mortar has a certain degree of 3D printing performance, as shown in Fig.5. To a certain extent, the degree of fluidity can restrict the scope of the $3 \mathrm{D}$ print performance. However, it is to be noted that there is no strong linear relationship between the printability and the flow ability of the mortar. With the same fluidity range, the thickener group (green dot in Fig. 1) enhances the number of stable printing layers with lower single-layer stacking deformation. From this, we can see the $3 \mathrm{D}$ print mortar should be appropriate to improve the cohesion of getting better 3D printing performance under the premise of a certain fluidity.

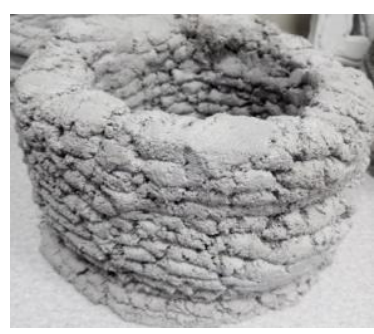

Fig.3 Effect of dry mortar

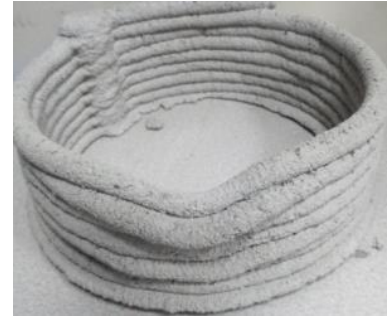

Fig.4 Effect of flow mortar

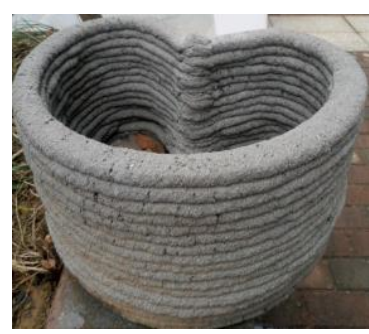

Fig.5 Effect of suitable mortar 


\subsection{The effect of the print layer on Process}

By printing closed graphics, test study single layer height,

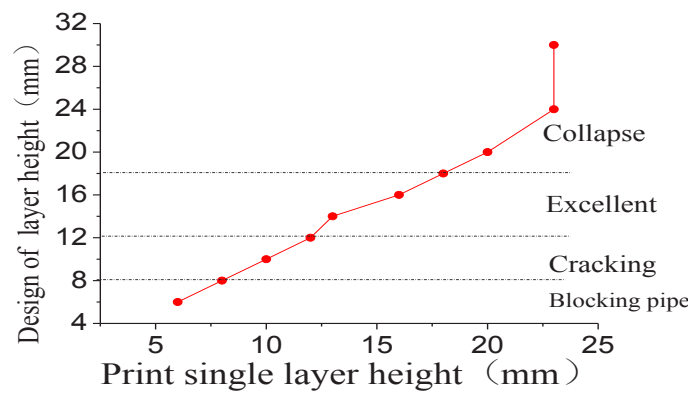

Fig.5 Effect of single layer height width and apparent effect using mortar mix ratio in the chapter 2.2(the flow performance range $210 \pm 20 \mathrm{~mm}$ ).
According to Fig.5, we can see that the layer height have a more obvious effect on the $3 \mathrm{D}$ printing effect. When the single layer height is more than $20 \mathrm{~mm}$, because of the deformation of the slurry causing the structural deformation to collapse, the mortar cannot pile up according to the design trajectory. As shown in Fig.6, if the single layer height is lower than $12 \mathrm{~mm}$, the mortar extrusion volume is greater than the single layer limit. This will increase the single layer width, and the edges of the print layer are cracked. When the single layer height

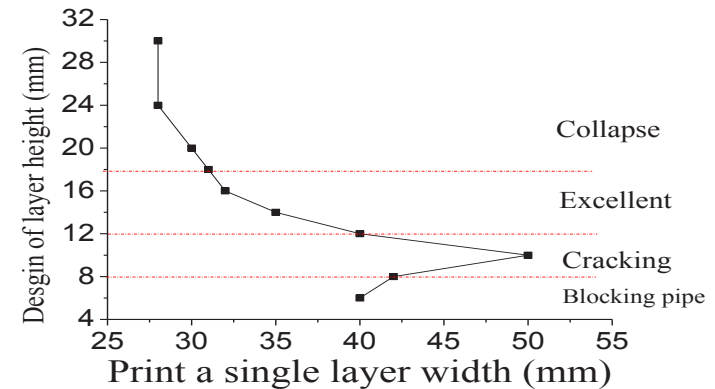

Fig.6 Effect of single layer width

is lower than $8 \mathrm{~mm}$, the mortar cannot be discharged. And around the nozzle, the mortar accumulates together to form a closed structure, and even cause the phenomenon of blocking, as shown in Fig.7. But when single layer height is between $12-18 \mathrm{~mm}$, the nozzle extrusion pressure concentration problem is not significant. The printing process is relatively smooth. Therefore, in the test conditions, the best single-layer height and nozzle diameter ratio is between 0.4-0.6.

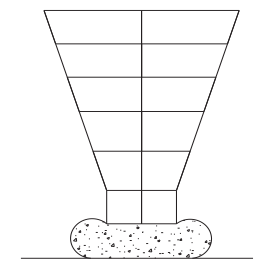

Lower layer height

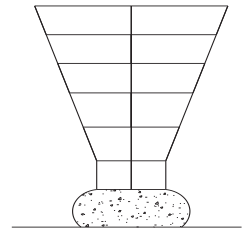

Suitable layer height

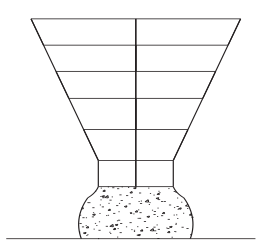

Higher layer height

Fig.7 3D print effect of different single layer high

\subsection{The Effect of Printing Speed on Process}

By printing $13 \mathrm{~mm}$ layer height closed graphics, test study single layer height, width and apparent effect using mortar mix ratio in the chapter 2.2(the flow performance range $210 \pm 20 \mathrm{~mm}$ ).

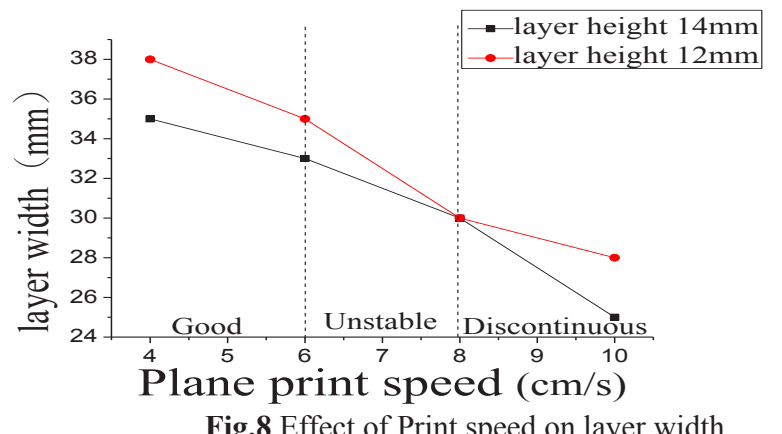

Fig.8 Effect of Print speed on layer width

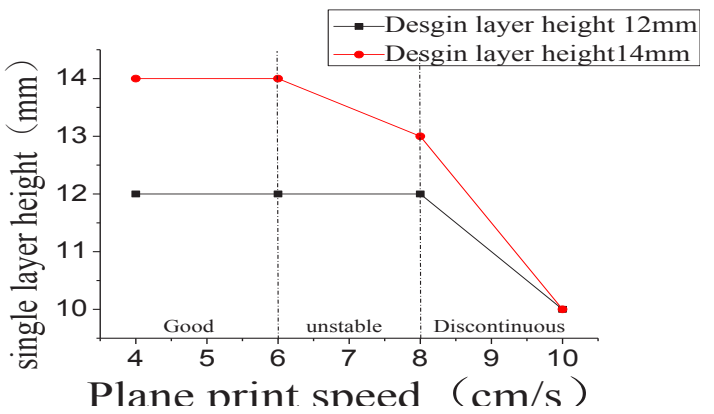

Fig.9 Effect of Print speed on layer height
According to the fig.8, we can see that under the same layer height and print volume, different printing speed directly affects the effect of component molding. In the range of suitable layer height, the excessive speed will have an impact on single layer stack stability. When the plane running speed is more than $6 \mathrm{~cm} / \mathrm{s}$, the width of the single layer is biased. When the speed exceeds
$8 \mathrm{~cm} / \mathrm{s}$, the extrusion speed of the mortar cannot reach the moving speed. And in this test case, the most appropriate flat print speed should be between $4-8 \mathrm{~cm} / \mathrm{s}$. 


\subsection{The Effect of Pipe length, arrangement and delivery equipment on Process}

By printing $14 \mathrm{~mm}$ layer height closed graphics with $2 \mathrm{~m}$,
$3 \mathrm{~m}, 4 \mathrm{~m}$ of $\varphi 32 \mathrm{~mm}$ high pressure rubber tube, test study single layer height, width and apparent effect using mortar mix ratio in the chapter 2.2(the flow performance range $210 \pm 20 \mathrm{~mm}$ ).

Table 2 The Effect of Pipe length, arrangement

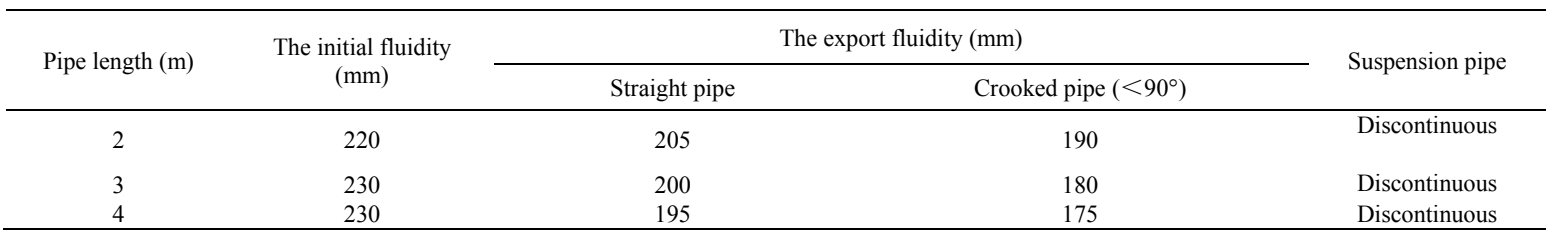

The mortar material is pumping from the screw pump to the $3 \mathrm{D}$ printer. Due to the limited diameter of the screw pump output, the diameter of the rubber tube can only be selected as $32 \mathrm{~mm}$. During the printing test, the performance of the mortar is reduced by pumping, and the mortar performance decreases with the length of the pipe. At the same time, when the rubber tube is inevitably bending, the load of the pump is obviously increased, and the performance of the extruded mortar is

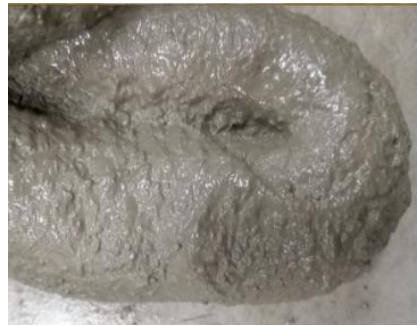

The initial state of mortar also significantly reduced compared with the initial state, as shown in fig.10. And when the rubber tube is suspended, the mortar with fluidity between $210 \pm 20 \mathrm{~mm}$ cannot be continuously printed. Therefore, in the screw pump and rubber tube conditions, 3D printing should be based on construction requirements to select the appropriate length of the pipeline, and should ensure that the pipeline straight to avoid the pipe bending and suspension, it will help reduce the risk of blocking.

Fig.10 The effect of the conveying pipe

At the same time, it is found that the metal screw and rubber bushing of the screw pump produced some frictional heat during operation. If the extrusion rate is matched with the screw rotation rate, the heat was taken away from the mortar without affecting its pumping efficiency. However, if the material performance is degraded or the local pipe is slightly clogged, the heat

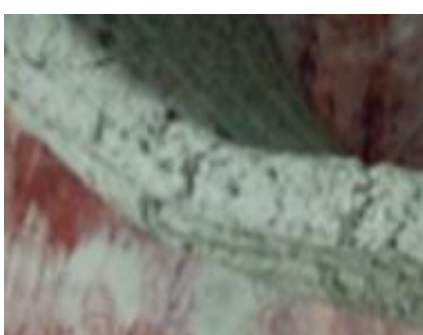

The export state of mortar

generated by the screw pump will be insufficient for rapid dissipation, which will cause further deterioration of the mortar performance, resulting in pipe plugging. According to the experience of the test, the impact of printing equipment on the success of $3 \mathrm{D}$ print is shown in table 3 :

Table 3 The impact of printing equipment on the success of 3D print

\begin{tabular}{ccccc}
\hline \multirow{2}{*}{ Influencing factors } & Equipment performance degradation & Pipe length & Distribution method & Sealability \\
\cline { 2 - 5 } Control measures & Extremely & Middle & High & Extremely \\
\hline & To remove hard materials in time & $\begin{array}{c}\text { According to the } \\
\text { component size }\end{array}$ & Try to remain straight \\
airtightness
\end{tabular}

\section{Conclusion}

In the $3 \mathrm{D}$ printing with cement-based materials, the material properties and process parameters have a great impact on the actual printing process. In the test conditions, the results show that the best single-layer height and nozzle diameter ratio are between 0.4-0.6. The best parameters for the equipment are: the output displacement is $9 * 10^{-2} \mathrm{~m}^{3} / \mathrm{h}$, the printing speed should be controlled in $4-8 \mathrm{~cm} / \mathrm{s}$; At the same time, 3D printing should try to choose a shorter length of the pipeline, and should ensure that the pipeline straight to avoid the pipe bending and suspension, it will help reduce the risk of blocking.

\section{Acknowledgements}

This paper is supported by Cscec Fund Project (cscec-2014-z-33).

\section{References}

1. LI Dichen, HE Jiankang,TIAN Xiaoyong,etc. 
Additive Manufacturing: Integrated Fabrication of Macro/Microstructures [J]. Journal of Mechanical Engineering, 2013,06:129-135.

2. WANG Zhonghong, LI Yang, ZHANG Manying. The Present Situation and Development of China's $3 \mathrm{D}$ Printing Industry [J]. Economic Review,2013,28(1):90-93.

3. HUANG weidong. How to rationally view the material manufacturing (3D printing) technology [J].Adbanced Materials Industry,2013(8):9-12.

4. LIU Yuanyuan, ZHANG Fuhua, CHEN Weihua, etc. CAD/CAM System and Experimental Study of Biological 3D Printing Composite [J]. Journal of Mechanical Engineering, 2014,50 (15):147-154.

5. T.T.Le,S. A. Austin,S.Lim, R.A.Buswell, A.G.F.Gibb, T.Thorpe. Mix design and fresh properties for high-performance printing concrete[J].Materials and tructures, 2012, 45:1221-1232.

6. JIANG Jianing, GAO Yuxin,WU Xiong, etc. Research status and problem analysis of 3D printing concrete [J]. Concrete, 2015, 05: 62-65. 